\title{
History of Skin Graft Harvesting- A Mini Review
}

\section{Sundaram Rajaram* and Gauthami Sundar}

Oral and Maxillofacial Surgery Department, International Medical Center, United

Arab Emirates

*Corresponding Author: Sundaram Rajaram, Oral and Maxillofacial Surgery

Department, International Medical Center, United Arab Emirates.
Received: August 17, 2021

Published: September 11, 2021

(C) All rights are reserved by Sundaram

Rajaram and Gauthami Sundar.

\begin{abstract}
The skin grafting is an age old surgical reconstruction technique that is still being practiced. It is such a versatile procedure that it still holds a place in the reconstructive ladder forming an important treatment option in the field of reconstruction. The need of the situation has seen a sequence of changes in the skin grafting techniques that has led to the use and invention of varying armamentarium suiting each of them. This article is a mini review of the history of techniques in skin graft harvest and the armamentarium involved.
\end{abstract}

Keywords: Skin Grafting; Split Thickness Skin Grafts; Full Thickness Skin Grafts; History of Skin Grafting

\section{Introduction}

Wound healing is one of the most eventful phenomena seen in physiology. Wounds healing with primary intention heal the best with minimal complications. Wounds that heal otherwise (secondary intention) are bound to have added complications that can happen like infection, scarring, scar contracture. prevention of such issues are done by harvesting grafts or flaps to cover up such defects in order to promote primary intention wound healing thereby wound heals the best. Skin Grafts become the first line choice of covering such defects. Since time immemorial, skin grafts had been practiced and have been identified with many parts of the globe at varied timelines.

History of skin grafting and armamentarium

The history of free skin grafting dates back to as early as $600 \mathrm{BC}$ in ancient India where the defects of the ears nose and lips were treated using free gluteal grafts and skin grafts [1].
Tile maker caste have been known for practicing free skin grafts, harvested from the gluteal region which was prepared by beating with wooden slippers until significant swelling had taken place they also used a secret cement for adhesion of the skin grafts which was called the "ancient Indian method" [2].

After a long stint of time it was G. Baronio in the $18^{\text {th }}$ century who documented the use of skin grafting so his skin grafting techniques involved tail of a sheep as a donor sites. All the transplanted skin grafts on the same animal were found to be remarkably successful [2]. Bunger in 1823, inspired by "Ancient Indian Method" harvested free whole thickness skin grafts from the thigh for covering the nasal defects in which he found moderate success. Sir Astley cooper transplanted the skin from the amputed thumb for covering the stump defect [3].

Reverdin in $19^{\text {th }}$ century introduced "Epidermic grafts" which was popularly called as "the pinch grafts". In this technique the skin 
was pinched up and cut off and were placed on the healing granulating wounds, there by covering the wound. Although the pinch graft were very popular cosmetically it gives very poor results [5].

Following Reverdin Oilier in the late $19^{\text {th }}$ century transplanted much larger films of skin and found success in it. Carl Thiersch (in 1886) presented a method of skin grafting which involved large films of epidermis with less dermal components which is the same as oilier. Later this technique was named as Oilier-Thiersch graft and also has been called the "split graft".

In 1875 John Reissberg Wolfe of Glasgow successfully covered a lower eyelid defect transplanted from the arm. Since the introduction of Oilier Thiersch grafts and many other surgeons, practising skin harvesting with differential thickness, leading to better donor site healing the need for better sophisticated instruments found its rise [6].

Blair knife, Catlin knife and Ferris - Smith knife were the simplest of knifes that were used to harvest split thickness skin grafts in the initial days [7].

Vilray Papin Blair in 1930 tactfully used the suction apparatus to place the skin under tension and used a knife to harvest skin grafts [6]. John Staige David in 1909 presented a detailed account of using a Catlin knife in harvesting skin grafts. Hofmann developed a guarded knife which permitted him to adjust the depth of the skin to be sliced which was regulated by screws. However, Ricardo Finochietto, invented a revise version of Hoffmans knife which became very popular [9]. So henceforth, regulating the thickness of skin grafts became the order of practice.

Graham Humby in England was the first to use a depth control knife in harvesting skin grafts. He added roller to the Blair knife thereby making it modified. The distance between the both was adjustable by means of a calibration device [10]. Humby later modified his device in which the tension on the skin was created using tiny needles on a cross bar which pierce the skin to depth of oneeighth of an inch. It was having another frame work in which is a knife with an adjustable rolling and sling guard. This device was mainly used on the limbs [11]. However, this technique was very combersone because of the size of the frames used. So Humby discarded the large frame and used only a solid blade. The knife had a rod which is connected to the upper surface with screws that allow it to control the depth [12].

Denis Charlis Vodenham introduced replaceable blades thus avoiding the frequent disadvantage of sharpening the blade and it also enjoys the advantage of having a better hygiene and minimal drag from bluntness [13,14]. Braithwaite Fenton in 1955 introduced the knife in which the blade need not be dismantled [15]. But Braith Waite Knife has a tendency to make the skin rolled up during harvest. This required an assistant to hold the free ends of the skin graft while being harvested. It can also lead to uneven thickness of the harvested skin and in some cases the skin grafts can also get cut in the midway [16] all this disadvantages were owed to the roller that slide to and fro along its long axis. Watson john in 1960 identified the problem and introduced a knife that had a rod with no independent movement [17] the drag that used to be seen while using these knifes could be avoided by lubricating the skin surface using liquid paraffin [18] Cobbett made a modification to Braithwaite knife by cutting a' D' section instead of a circular hole in the guard end. This was done to avoid the drag and rolling up of the skin [16].

Goullian used straight razor with a handle that can cut different thickness of the skin [19] snow used Shick injector razor in harvesting skin grafts [20]. Shoul modified a Gillette safety razor for harvesting skin grafts [21] silver in 1959 also joins the list of people who used razors for skin grafting [22-24] in 1939 Dr Earl Padgett invented a device which was based on the adhesion-traction principle named as dermatomes following him harry M. brown in vented an electric dermatome. There were further modification in the dermatome like the Pagette dermatome, Reese dermatome, the brown dermatome, the Stryker dermatome and the Castroviejo [25-27].

\section{Limitations}

The content of this article is the result of the available datas in googlescholar and pubmed journals. The missed articles and information are beyond the scope of reach owing to non retrievability, different language and non-availability in the internet.

\section{Conclusion}

Skin graft is a reconstructive technique that has been in practice for a long time in history. The technique has a simple physiology 
which remains unaltered till date. The techniques involved in skin graft harvesting has seen a gradual evolution leading to the modern day devices of effective skin graft harvesting. It is these techniques of harvest and fixation that determine the success of the graft other than the systemic factors. Any surgeon should aim at perfecting these techniques for achieving best results.

\section{Bibliography}

1. Chick LR. "Brief history and biology of skin grafting". Annals of Plastic Surgery 21 (1988): 358-365.

2. Davis JS. "Address of the President: The Story of Plastic Surgery". Canadian Medical Association Journal 113 (1941): 641656.

3. Tiersch C. "Über Hautverplanzung". Verh Dtsch Ges Chir (1886): 15-17.

4. Gerrie JW. "The Choice of Skin Grafts in Plastic Surgery". Canadian Medical Association Journal 44 (1941): 9-13.

5. Converse JM. "Early skin grafting in war wounds of the extremities”. Annals of Surgery 115 (1942): 321-335.

6. Converse JM and Bauer RO. "Transplantation of Skin”. In: Converse JM, editor. Reconstructive Plastic Surgery: Principles and Procedures in Correction, Reconstruction and Transplantation. $1^{\text {st }}$ edition. Philadelphia: W. B. Saunders (1964): 26-32.

7. Davis JS. "Plastic Surgery Its Principles and Practice". $1^{\text {st }}$ edition. Philadelphia: P. Blakiston's and Son; 1919.

8. Davis JS. "Skin Grafting at the Johns Hopkins Hospital; Discussion on Modern Methods of Skin Grafting". Annals of Surgery 50 (1909): 542-549.

9. Converse JM. "Grafts of Skin and Mucosa”. In: Converse JM, editor. Kazanjian and Converse's surgical treatment of facial injuries. 1. $3^{\text {rd }}$ edition. Baltimore: Williams and Wilkins (1974): 531-554.

10. Clarkson P. "The Humby". British Medical Journal 2 (1952): 1101.

11. Humby G. "Apparatus for Skin Grafting”. British Medical Journal 1 (1934): 1078.
12. Humby G. "Modified Graft Cutting Razor". British Medical Journal 2 (1936): 1086.

13. Bodenham DC. "A new type of knife for cutting skin grafts, using replaceable blades". British Journal of Plastic Surgery 2 (1949): 136.

14. Bodenham DC. "A new type of knife for cutting skin grafts, using replaceable blades". Plastic and Reconstructive Surgery 5 (1950): 108.

15. Braithwaite F. "Modification of Humby knife". Lancet 268 (1955): 1004.

16. Cobbett J. "A modification of the Braithwaite knife". British Journal of Plastic Surgery 21 (1968): 216-217.

17. Watson J. “A skin-grafting knife”. Lancet 2 (1960): 687-688.

18. Brown JB and Lee WE. "The repair of surface defects of the hand Skin grafting". Annals of Surgery 107 (1938): 952-971.

19. Goulian D Jr. "Anew economical dermatome". Plastic and Reconstructive Surgery 42 (1968): 85-86.

20. Snow JW. "Safety razor dermatome". Plastic and Reconstructive Surgery 41 (1968): 184.

21. Shoul MI. "Skin grafting under local anesthesia using a new safety razor dermatome". The American Journal of Surgery 112 (1966): 959-963.

22. Silver HL. "A new dermatome". Canadian Medical Association Journal 80.10 (1959): 828.

23. Silver HL and Gerrie JW. "A new dermatome: Discussion on modern methods of skin grafting, the choice of skin grafts in plastic surgery". Canadian Medical Association Journal 80 (1959): 828.

24. Silver HL and Kilner TP. "A new dermatome: The thiersch graft. its preparation and uses". Canadian Medical Association Journal 80 (1959): 828.

25. Bennett JE and Miller SR. "Evolution of the electro-dermatome". Plastic and Reconstructive Surgery 45 (1970): 131-134.

26. Stark RB. "John Davies Reese and the Reese dermatome". Annals of Plastic Surgery 2 (1979): 80-83. 
27. Castroviejo R. "Electro-Keratotome for the dissection of lamellar grafts". Transactions of the American Ophthalmological Society 56 (1958): 402-408.

Volume 5 Issue 10 October 2021

(C) All rights are reserved by Sundaram Rajaram and Gauthami Sundar. 